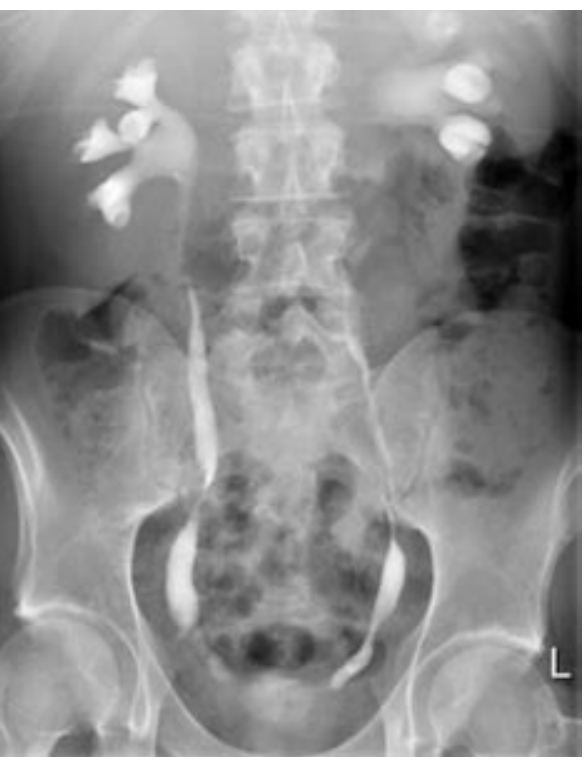

\section{AN EMERGING PROBLEM}

\section{Urinary tract disease associated with chronic ketamine use}

Regarding the case study by Dhillon et al, ${ }^{1}$ we have seen an alarming increase in people presenting to urological services in South West England with bladder symptoms associated with chronic ketamine use. Two case series in Hong Kong and Canada have been published, but ketamine associated bladder pathology has not been reported in the UK. ${ }^{23}$

Over the past two years, nine patients have presented to local urologists with symptoms of severe urinary frequency, urgency, macroscopic haematuria, and suprapubic pain. They all had a history of chronic ketamine use, either recreationally or therapeutically for chronic pain. Urine culture results were negative and cystoscopy showed a contracted shrunken bladder with erythema and contact bleeding. Histological examination showed ulcerative cystitis and a severely denuded urothelium.

They were given analgesics and encouraged not to use ketamine. Complications included hydronephrosis and renal impairment. They were treated by nephrostomy and insertion of a suprapubic catheter to manage painful urge urinary incontinence.

Discussions with the patients and contact with Bristol Drugs Project indicated that these cases are just the "tip of the iceberg." Recreational use of ketamine is increasing in the West Country. Urinary symptoms are often reported by ketamine users. Symptoms may improve and even reverse once ketamine intake is stopped, but two of our patients still have intractable symptoms despite abstaining. The pathological mechanism of ketamine is not known, but chronic ketamine use may affect the whole urinary tract. Some patients have acute renal failure, renal papillary necrosis, and ureteric obstruction (Peggy Chu, personal communication). Further work is needed to establish the mechanism of action of ketamine on the urinary tract and to educate healthcare professionals who may come in contact with these patients. Ketamine users must be made aware of the serious and potentially irreversible sequelae of chronic ketamine use, and we are working with Bristol Drugs Project to develop evidence based harm reduction advice for this population.

Angela M Cottrell clinical research fellow, Bristol Urological Institute, Southmead Hospital, Bristol BS10 5NB angecottrell@hotmail.com

Rachel Athreeres volunteer manager, Bristol Drug Project, Bristol BS2 8PE

Pete Weinstock senior practitioner, Bristol Drug Project, Bristol BS2 8PE

Kate Warren urology registrar, Weston General Hospital, Weston super Mare BS23 4TQ

David Gillatt consultant urological surgeon, Bristol Urological Institute, Bristol

Competing interests: None declared.

1 Dhillon BS, Nuttall MC, Coull N, O'Brien TS. Minerva. BMJ 2008;336:898. (19 April.)

2 Chu PS, Kwok SC, Lam KM, Chu TY, Chan SW, Man CW, et al. "Street ketamine"-associated bladder dysfunction: a report of ten cases. Hong Kong Med J 2007;13:311-3.

3 Shahani R, Streutker C, Dickson B, Stewart RJ. Ketamineassociated ulcerative cystitis: a new clinical entity. Urology 2007;69:810-2.

\section{CONFIDENTIALITY}

\section{Communications with primary care trusts: another challenge}

Bourke and Wessely are to be commended for their useful summary of medical confidentiality. ${ }^{1}$ However, there is a new challenge in this area-communication with primary care trusts and other organisations that control funding of clinical care. A secretary in my NHS trust was ordered by an administrator from a nearby primary care trust to forward a clinic letter on a patient whom I had assessed in my neuropsychiatry clinic, so that the trust could decide whether a follow-up appointment was to be "authorised." We were told that failure to forward the letter would prevent the patient from being seen again. No account was taken of the sensitivity of information contained in the letter. There was no reference to obtaining the patient's consent. The primary care trust representative was not a clinician and was not writing on behalf of a clinician. Neither she nor the primary care trust formed part of the clinical team, and the decision they were making was not necessarily in the patient's interest-it was purely about funding.

It is ironic that in these times where legitimate access to patient information for research purposes is becoming ever more difficult, ostensibly to protect patient confidentiality, flagrant breaches are being made in the service of financial control.

Anthony S David professor, Institute of Psychiatry, King's College, London SE5 8AF

a.david@iop.kcl.ac.uk

Competing interests: None declared.

1 Bourke J, Wessely S. Confidentiality. BMJ 2008;336:888-91. (19 April.)

\section{SCREENING FOR AORTIC ANEURYSM}

\section{Detection is not as harmful as it} might seem

Johnson argues that screening for abdominal aortic aneurysm may cause psychological harm by alerting people that they have a condition that nothing can be done about but that can cause sudden death. ${ }^{1}$ This notion is contradicted by a large literature on how people respond to aneurysm screening ${ }^{2}$ and other health risk information. ${ }^{3}$ It is also at odds with psychological theories of self regulation, which describe the complex ways that humans maintain equilibrium while responding to all sorts of threats.

Anxiety is a common and adaptive initial response to risk notification, but it usually dissipates within a month. ${ }^{3}$ Pretest preparation can mitigate anxiety, but there is no evidence to support the statement that "any member of the public taking the test will need intensive counselling about the possible consequences that screening might have for their future lives and psychological wellbeing." ${ }^{1}$ The way people think and feel before screening seems to be a stronger predictor of post screening states than test results-those who are depressed before screening are depressed afterwards, whatever the results. ${ }^{4}$ Poorer self assessed health seems 
to be a predictor not a consequence of the detection of an aneurysm. ${ }^{5}$

Not everyone participates or responds to questionnaires on emotional states. People who do not respond seem to have poorer emotional outcomes. However, the large robust studies that have assessed emotional outcomes after detection of an aneurysm provide no evidence to suggest that this generates psychological harm of the kind imagined by Johnson.

Theresa M Marteau professor of health psychology, King's College, London SE1 9RT

theresa.marteau@kcl.ac.uk

Competing interests: None declared.

1 Johnson JN. Should we screen for aortic aneurysm? No. BMJ 2008;336:863. (19 April.)

2 Khaira HS, Herbert LM, Crowson MC. Screening for abdominal aortic aneurysm does not increase psychological morbidity. Ann R Coll Surg Engl 1998;80:341-2.

3 Shaw C, Abrams K, Marteau TM. Psychological impact of predicting individuals' risk of illness: a systematic review. Soc Sci Med 1999;49:1571-98.

4 Broadstock M, Michie S, Marteau TM. The psychological consequences of predictive genetic testing: a systematic review. EurJ Hum Genet 2000;8:731-8.

5 Marteau TM, Kim LG, Upton J, Thompson SG, Scott AP. Poorer self assessed health in a prospective study of men with screen detected abdominal aortic aneurysms: a predictor or a consequence of screening outcome? $]$ Epidemiol Commun Health 2004;58:1042-6.

\section{Some reasons for lukewarm support are purely political}

Johnson argues that a death rate of one in 14 from elective abdominal aortic aneurysm repair means that screening is futile. ${ }^{1}$ Many specialist vascular units have elective mortality rates of $5 \%$ or less for open repair and mortality rates of less than $2 \%$ for endovascular repair (as confirmed by the EVAR trial and Dr Foster). Even a one in 14 death rate is better than $80 \%$ mortality from rupture. I and many of my colleagues (including nursing staff) are weary of counselling the grieving wives and children of men who suffer

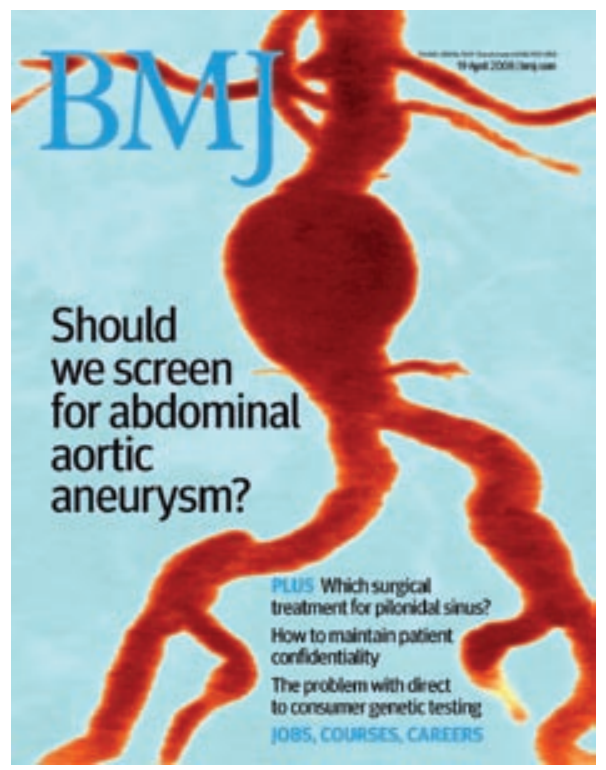

unexpected, agonising, and bloody deaths.

Detection of an abdominal aortic aneurysm provides one important benefit that Johnson ignores-patient choice. Patients who die of rupture are denied that choice. Johnson suggests that screening leads to unacceptable levels of anxiety for those placed on surveillance programmes. This claim is not supported by the literature. Screening for abdominal aortic aneurysm also compares favourably, in cost effectiveness terms, with breast and cervical screening.

I suspect that the government has not funded abdominal aortic aneurysm screening (and even now provides only lukewarm support) because few votes will be won (and more pensions will need to be paid) by saving the lives of men of retirement age. As a politician, Johnson should understand this all too well. Jonathan Beard consultant vascular surgeon, Sheffield Vascular Institute, Northern General Hospital, Sheffield S57AU Jonathan.D.Beard@sth.nhs.uk

Competing interests: None declared.

1 Johnson JN. Should we screen for aortic aneurysm? No. BM/ 2008;336:863. (19 April.)

\section{No conclusion for men aged 65-75 who have never smoked}

Brearley cites the US Preventive Services Task Force (USPSTF) in support of abdominal aortic aneurysm screening. ${ }^{1}$ However, it makes no recommendation for or against screening in men aged 65-75 who have never smoked. The task force did find good evidence that screening in these men leads to decreased abdominal aortic aneurysm specific mortality, but they have a lower prevalence of large abdominal aortic aneurysms than men who have ever smoked, so the potential benefit is small. There is good evidence that screening and early treatment lead to important harms, including increased number of operations with associated clinically significant morbidity and mortality, and short term psychological harm. The task force concluded that the balance between the benefits and harms of screening for abdominal aortic aneurysm is too close to make a general recommendation in this population. ${ }^{2}$

The men invited for screening should be given this information as well as the likelihood that they will benefit-less than one in 1000 . Consent for screening is only valid if it is well informed.

John Doherty medical director, IAEA, Vienna, Austria 1400 j.doherty@iaea.org

Competing interests: None declared

1 BrearleyS. Should we screen for abdominal aortic aneurysm? Yes. BMJ 2008;336:862. (19 April.)

2 US Preventive Services Task Force. Screening: abdominal aortic aneurysm. 2005. www.ahrq.gov/ clinic/uspstf/uspsaneu.htm.

\section{GLOBAL ACCESS TO VACCINES}

\section{Vaccine science and commerce: never the twain shall meet?}

Chokshi and Kesselheim suggest some reasons why effective vaccines are unavailable in poorer countries. ${ }^{1}$ The main reason is that most wealthy countries demand a solution (vaccine) for infectious diseases of public health importance, while poorer countries do not-and should they do so, they are largely ignored. This explains the scant attention paid to important issues such as improving measles and tuberculosis vaccines and the strong focus on new vaccines irrespective of their desirability and feasibility in developing countries. What is worse is that many manufacturers have realised the potential of marketing in developing countries (large population and variable spending power) and are ruthlessly exploiting the weak decision making systems there to aggressively promote products that are often not required.

Chokshi and Kesselheim state that "difficulty in disseminating well established vaccines casts doubts on our ability to promote widespread use of new ones," 1 but the opposite is being witnessed in most developing countries today. Although coverage with vaccines such as against diphtheria, pertussis, and tetanus and measles have still not reached levels required to eradicate/eliminate/control these "old" problems, new vaccines are being aggressively promoted not only by manufacturers but also directly and indirectly by trusted organisations such as the World Health Organization, national bodies of experts, and perhaps articles such as Chokshi and Kesselheim's.

Joseph L Mathew assistant professor (paediatrics), Advanced Paediatrics Centre, Postgraduate Institute of Medical Education and Research, Chandigarh 160012, India jlmathew@rediffmail.com

Competing interests: None declared.

1 Chokshi DA, Kesselheim AS. Rethinking global access to vaccines. BMJ 2008;336:750-3. (5 April.)

\section{Poor nations are being lured into a debt trap}

With regard to access to papillomavirus vaccine (Gardasil), ${ }^{1}$ let us assume that the vaccine covers all strains causing cervical cancer. In India $21 \mathrm{~m}$ girls would have to be vaccinated each year to avoid 260000 deaths at a cost for the vaccine alone of $\$ 8400 \mathrm{~m}$. The programme would have to be sustained for over 20 years. Even if it prevented all cervical cancers, it would reduce by only $2 \%$ the $10.9 \mathrm{~m}$ deaths caused by infectious diseases. ${ }^{2}$ If the cost of the vaccine fell to $\$ 1$ per dose, it would still cost $\$ 63 \mathrm{~m}$ for the vaccine alone. 


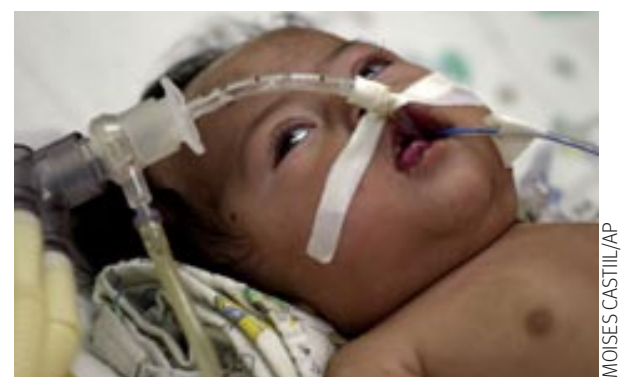

So rotavirus causes 440000 deaths each year. ${ }^{1}$ If we have a vaccine that covers all the human strains (an overgenerous assumption for India $\left.{ }^{3}\right), 126 \mathrm{~m}$ children around 2 months of age will need to be vaccinated three times ( $378 \mathrm{~m}$ doses). ${ }^{2}$ At the present public sector cost of $\$ 7 /$ dose $^{4}$ the cost of the vaccine will be $\$ 7938 \mathrm{~m}$. This expenditure will bring down the deaths due to infections by $4 \%$.

The compulsion to increase demand for these vaccines comes from the manufacturers not the consumer. That is why organisations such as GAVI have to give grants in aid to poor countries to offload these vaccines. It is hoped that poor countries can be persuaded to continue to use the vaccine after the aid is withdrawn. Poor nations are lured into a debt trap by such schemes.

Traditionally vaccines are tested by multinational manufacturers in the United States and Europe and then in developing countries as supplies and competition increase and the cost of vaccine comes down. This is in accordance with the Helsinki Declaration that trials be done in populations who are directly to use the drug.

Chokshi and Kesselheim point out that Gardasil was produced in the United States and Australia and tested in Brazil, India, and Costa Rica. ${ }^{1}$ The cost of research is halved by conducting it in developing countries, ${ }^{5}$ and the compensation for adverse events is much lower. In an upside down world where profits are paramount, this arrangement "could help meet international demand for low cost products." The fates of human guinea pigs in developing countries don't count for much.

Jacob M Puliyel consultant paediatrician and head of department puliyel@gmail.com

Ashutosh Shrivastava resident in paediatrics, St Stephen's Hospital, Tis Hazari, Delhi 110054, India

Competing interests: None, except that JMP and AS live in a developing country-India.

1 Chokshi DA, Kesselheim AS. Rethinking global access to vaccines. BM/ 2008;336:750-3. (5 April.)

2 World Health Organization. Revised global burden of disease 2002 estimates. www.who.int/healthinfo/ bodgbd2002revised/en/index.html

3 Ramani S, Kang G. Burden of disease of group A rotavirus infection in India. Indian J Med Res 2007;125:619-32.

4 PATH Rotavirus. www.rotavirusvaccine.org/documents/ RotaQA_an06.pdf.

5 Sharma D. India pressed to relax rules on clinical trials. Lancet 2004;363:1528-9.

\section{Vaccine sale is not tailored to improving India's health}

Measles is still a big killer, especially in poor malnourished children in India. Yet professional bodies have yet to recommend to the government the inclusion of the measles, mumps, and rubella (MMR) vaccine in the national immunisation programme. ${ }^{1}$ The Indian Academy of Paediatrics has, however, recommended vaccination against hepatitis $B$. The incidence of hepatitis $B$ in India is lower than originally thought, so the costs of vaccination may outweigh the benefits and its inclusion in the national programme may not be justified.

Vaccination against Haemophilus influenzae type $B$ is also being promoted aggressively by drug companies with the acquiescence of professional academies. Infections, especially meningitis, caused by haemophilus influenza in young children are serious, causing a high proportion of death and disability. The epidemiology of haemophilus influenza in India and its incidence in Indian children are not known, so the recommendations have been made without a risk-benefit analysis.

Alexander Mathew chief of paediatrics, Lisie Hospital, Kochi, Kerala 682018, India dralexmathew@gmail.com

Competing interests: None declared.

1 Chokshi DA, Kesselheim AS. Rethinking global access to vaccines. BMJ 2008;336:750-3. (5 April.)

\section{Vaccine requirements compete with basic needs of poor people}

Chokshi and Kesselheim make a strong case for developing countries to invest in an evidence base for developing and appropriately using newer vaccines. ${ }^{1}$ However, an infrastructure of the required research and information systems is entirely absent in developing countries and its creation would require the complete revamping of current public health systems. Those who promote vaccines as the most cost effective interventions for poor people never take into account the costs of erecting the health systems to deliver them and monitor their efficacy and safety.

The authors quote Amartya Sen to show the opportunities that open up for poor people in developing countries from modern health systems with delivery of vaccines. However, these people have competing needs for food, shelter, water, sanitation, and education. In reality, vaccines compete with these other needs. One example is that the widely prevalent malnutrition in children in India results from lack of health education of their mothers because health workers are too busy delivering vaccines. Therefore we have some improvement in vaccine coverage in the last two decades in India while malnutrition in children has not declined. Onkar Mittal national convener, Centre for Health Policy Dialogue, New Delhi 110049, India o_mittal@rediffmail.com

Competing interests: None declared.

1 Chokshi DA, Kesselheim AS. Rethinking global access to vaccines. BMJ 2008;336:750-3. (5 April.)

\section{The lessons of history}

Chokshi and Kesselheim imply that the beliefs are unfounded of those who "believe that ensuring supplies of food and clean water and building roads will do more for public health than isolated interventions like vaccines." ${ }^{1}$ We need only brush up on some history: in the United States the sharp decline in mortality due to infectious diseases, the main cause of death there in the early part of the 20th century, happened before the specific medical technology for each infectious disease had developed. ${ }^{2}$

c Sathyamala coordinator, public report on health, Council for Social Development, New Delhi 110003, India csathyamala@gmail.com

Competing interests: None declared.

1 Chokshi DA, Kesselheim AS. Rethinking global access to vaccines BMJ 2008;336:750-3. (5 April.)

2 Mckeown T. The modern rise of population. New York: Academic Press, 1976.

\section{SURGERY FOR PILONIDAL DISEASE}

\section{Articles point to the creation of a cartel}

It seems that Bascom, an enthusiast for the distinctly unproven hair follicle theory, has been "suckered" into believing that the midline wound in pilonidal sinus surgery is the cause of the problem. ${ }^{1}$ McCallum et al's analysis of a rag bag of papers includes, disgracefully, some that reached their conclusions on the basis of telephone follow-up. ${ }^{2}$ That's no way to conduct proper research. Effectively, McCallum et al took a load of apples, oranges, and pears and tried to decide which was the "best" fruit. Fruitless! For example, they inform us that "recurrences after primary closure were higher." Of course they were. It is a much more demanding procedure in which ideally the full extent of the infected pilonidal sinus track needs to be stained and excised meticulously, but rarely is.

Pilonidal sinus surgery demands attention to the precise definition of the extent of the disease, good tissue care, haematoma avoidance, sterility, meticulous closure, and military precision in postoperative nursing. It also requires a regimen for preventing recurrence, with full patient advice and monitoring, rather 
than the speedy discharge or follow-up by phone that seemed to satisfy the authors.

It now seems that those of us who practise those principles will be ostracised unless we are on the Pilonidal Support Foundation's list of 58 surgeons who are "familiar with off-midline repairs." No doubt, patients will be encouraged to ask for our credentials. On the basis of such flimsy evidence, that sounds worryingly like the creation of a cosy cartel.

Peter J Mahaffey consultant plastic and reconstructive surgeon, Bedford Hospital, Bedford MK42 9DJ

peter.mahaffey@bedfordhospital.nhs.uk

Competing interests: PJM receives many referrals after failed pilonidal sinus surgery.

1 Bascom J. Surgical treatment of pilonidal disease. BMJ 2008;336:842-3. (19 April.)

2 McCallum IJD, King PM, Bruce J. Healing by primary closure versus open healing after surgery for pilonidal sinus: systematic review and meta-analysis. $B M$ J 2008;336:868-71. (19 April),

\section{REPRODUCTIVE LIBERTY AND DEAFNESS}

\section{Clause 14(4)(9) of embryo bill should be amended or deleted}

Amendments to the Human Fertilisation and Embryology Act 1990 are currently passing through the UK Houses of Parliament. ${ }^{1}$ Clause 14 , section 4, number 9 (lines 23-30, page 10) says that people or embryos known to have a gene, chromosome, or mitochondrion abnormality that confers a significant risk of serious physical or mental disability, serious illness, or other serious medical condition must not be preferred over those not known to have an abnormality.

This clause has been added to prevent positive selection of deaf donors deliberately to result in a deaf child, and one outcome would be that deaf parents could not use preimplantation diagnosis to select embryos with genes for deafness.

If passed, the bill would make it illegal for a deaf adult to donate gametes for in vitro fertilisation, even to close relatives. It would be illegal for deaf parents, using preimplantation genetic diagnosis, to implant embryos with the genes for deafness if normal embryos were available.

Actively selecting for deafness is controversial. However, research indicates that few people want to do this, ${ }^{23}$ and requests to clinics for the selection of "disability" are low. ${ }^{4}$ So, is it necessary to legislate against something that is unlikely to happen and for which guidelines already exist?

This section of clause 14(4)(9) is discriminatory. The wording implies that deaf people are less valuable than "hearing" people, and likewise for their embryos. This contradicts attempts by the UK government to recognise the equal status of deaf people in policy (through recognising British sign language) and in law (through equal rights for deaf people). Deaf people wish to have equal rights when making decisions about reproduction, even when genetic technology is involved. We are therefore arguing for this section of the clause to be amended or omitted from the UK Human Fertilisation and Embryology Bill.

Steve Emery research fellow, Department of Languages and Intercultural Studies, School of Management and Languages, Heriot-Watt University, Edinburgh EH14 4AS

Teresa Blankmeyer Burke bioethicist, Philosophy and Religion Department, Gallaudet University, Washington, DC 20002, USA

Anna Middleton consultant research genetic counsellor, Institute of Medical Genetics, School of Medicine, Cardiff University, Cardiff CF14 4XN

Middletona1@cardiff.ac.uk

Rachel Belk genetic counsellor and NIHR research fellow, Faculty of Medicine and Human Sciences, University of Manchester, Manchester M13 9PT

Graham Turner chair of interpreting and translation studies, Department of Languages and Intercultural Studies, School of Management and Languages, Heriot-Watt University, Edinburgh EH14 4AS

Competing interests: None declared.

1 Eaton L. Controversial embryo bill receives second hearing in Lords. BMJ 2007;335:1069. (24 November.) doi: 10.1136/bmj.39406.478241.DB.

2 Middleton A, Hewison J, Mueller R. Prenatal diagnosis for inherited deafness-what is the potential demand? J Genet Couns 2001;10;121-31.

3 Stern SJ, Arnos KS, Murrelle L, Welch KO, Nance WE, Pandya A. Attitudes of deaf and hard of hearing subjects towards genetic testing and prenatal diagnosis of hearing loss. J Med Genet 2002;39:449-53.

4 Baruch S, Kaufman D, Hudson KL. Genetic testing of embryos: practices and perspectives of US IVF clinics. Fertil Steril 2006; Sep 19 [Epub ahead of print].

\section{NICE ON INFECTIVE ENDOCARDITIS}

\section{A call for national monitoring of antibiotic prophylaxis}

The UK National Institute for Health and Clinical Excellence (NICE) recently published guidelines on antibiotic prophylaxis for preventing infective endocarditis in high risk patients with structural heart disease. ${ }^{12}$ The guidelines no longer recommend their use during dental and other invasive procedures of the respiratory tract, genitourinary tract, and upper and lower gastrointestinal tract-a considerable change from current practice. The guidelines apply to all high risk patients. The guidelines point to the lack of high quality evidence on whether antibiotics are effective in this situation or whether such procedures are linked to infective endocarditis. This was also highlighted in other recent guidelines, ${ }^{3}$ but they stopped short of recommending a change to current practice. This raises questions and anxiety in patients and those who treat them.

The report cites reactions to antibiotics (including anaphylaxis) as an argument against their use on a population scale, but in practice cardiologists can ask individual patients about previous antibiotic use and reactions.

Unlike most areas where NICE issues guidance, there are no randomised control trials on antibiotic prophylaxis for infective endocarditis. Small observational and casecontrol studies provide inconclusive evidence in favour of antibiotic prophylaxis. Infective endocarditis is not a notifiable disease in the UK and we know of no system that could accurately detect a rise in incidence on a national level corrected for the use of antibiotic prophylaxis in individual cases.

Infective endocarditis is a life threatening condition with overall mortality of around $20 \%{ }^{1}$ We call for a system that can robustly assess the outcome of this important change in practice to be in place alongside its implementation.

Neil Herring clinical lecturer in cardiovascular medicine, Oxford University specialist registrar in cardiology neilherring@doctors.org.uk

David C Sprigings consultant cardiologist, Northampton General Hospital, Northampton NN1 5BD

Competing interests: None declared.

1 National Institute for Health and Clinical Excellence. Prophylaxis against infective endocarditis. Clinical guideline. 2008. www.nice.org.uk/guidance/index. jsp?action $=$ bylD \&o=11938.

2 Richey R, Wray D, Stokes T; on behalf of the Guideline Development Group. Prophylaxis against infective endocarditis: summary of NICE guidance. BMJ 2008;336:770-1. (5 April.)

3 Wilson W, Taubert KA, Gewitz M, Lockhart PB, Baddour LM, Levison M, et al. Prevention of infective endocarditis: guidelines from the American Heart Association. Circulation 2007;116:1736-54

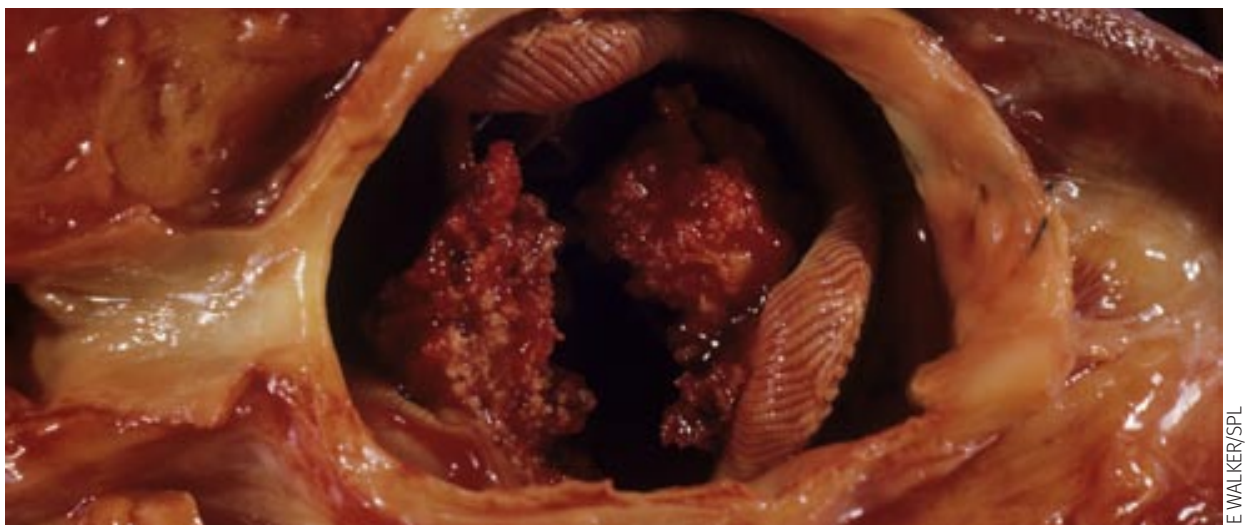

